\title{
ESTUdio de PASTAS CERÁMICAS DEL CENTRO-OESTE ARGENTINO (Mendoza, Argentina): Microscopía óptica y QEMSCAN
}

\author{
Cecilia Frigolé \\ https://orcid.org/0000-0002-2163-792X \\ CONICET, Laboratorio de Paleoecología Humana, \\ Facultad de Ciencias Exactas y Naturales, Universidad Nacional de Cuyo \\ cfrigole@gmail.com \\ Camila Riera-Soto \\ https://orcid.org/0000-0002-3426-1757 \\ Programa de Postgrado en Antropología mención Arqueología, \\ Universidad Católica del Norte, San Pedro de Atacama \\ cami.riera.soto@gmail.com \\ Andrew Menzies \\ https://orcid.org/0000-0003-0343-5758 \\ Departamento de Ciencias Geológicas, Universidad Católica del Norte \\ amenzies@ucn.cl \\ Monserratt Barraza \\ Unidad de Equipamiento Científico MAINI, Universidad Católica de Norte \\ mbarraza@ucn.cl \\ Anahi Benitez \\ https://orcid.org/0000-0002-8931-0448 \\ Laboratorio de Tectónica Andina, Facultad de Ciencias Exactas y Naturales, \\ Universidad de Buenos Aires \\ aanahibenitez@gmail.com \\ Diego Winocur \\ https://orcid.org/0000-0001-8354-7818 \\ Laboratorio de Tectónica Andina, Facultad de Ciencias Exactas y Naturales, \\ Universidad de Buenos Aires \\ diegowinocur@hotmail.com
}

\section{Resumen}

En este trabajo se integran resultados de dos técnicas analiticas utilizadas para el estudio de pastas cerámicas: microscopio petrográfico y Quantitative Evaluation of Minerals by Scaning Electron Microscopy (QEMSCAN), el cual se presenta como una innovación para el estudio de pastas. El objetivo consistió en explorar el potencial de complementariedad entre ambas técnicas. Para ello, se aplicaron análisis de QEMSCAN a muestras de material cerámico arqueológico provenientes del Noroeste de la provincia de Mendoza, en el Centro Oeste Argentino, que fueron estudiadas previamente en microscopio de polarización óptica. La información obtenida mediante QEMSCAN resultó coherente con los resultados del análisis por microscopio de polarización y permitió profundizar las observaciones realizadas a partir de los estudios petrográficos. Los análisis de QEMSCAN detectaron minerales de tamaños muy finos que componen la arcilla, cuya 
identificación presenta dificultades en el microscopio petrográfico, mientras que los estudios petrográficos permitieron interpretar los resultados obtenidos por el análisis automatizado. La aplicación conjunta de ambos análisis permitió caracterizar y discriminar pastas de procedencia diversa y vincular su composición con marcos geológicos locales y extraregionales. Consideramos que los análisis realizados mediante microscopio de polarización y QEMSCAN, brindan información complementaria, y su aplicación combinada guarda potencial para estudiar proveniencia de materiales cerámicos y manufactura de pastas.

Palabras clave: QEMSCAN, análisis petrográfico, cerámica arqueológica, Mendoza, Argentina.

\section{Abstract \\ STUDY OF CERAMIC PASTES OF WEST CENTRAL OF ARGENTINA (MENDOZA, ARGENTINA): OPTICAL MICROSCOPY AND QEMSCAN}

In this work, results of two analytical techniques used for the study of ceramic pastes are integrated: thin section petrography and Quantitative Evaluation of Minerals by Scaning Electron Microscopy (QEMSCAN), which is presented as an innovation for the study of pastes. The aim was to explore the potential of complementarity between both techniques. QEMSCAN analysis was applied to samples of archaeological ceramic material from northwestern Mendoza, Argentina, which were previously studied in an optical polarization microscope. The information obtained by QEMSCAN analysis was consistent with the results of the petrographic analysis, and made it possible to deepen the results of the petrographic studies. Petrographic analysis was necessary to interpret the results obtained by the application of automated QEMSCAN analysis. While the QEMSCAN analysis detected minerals of very fine sizes that make up the clay, whose identification is difficult in the petrographic microscope. The application of both analyses made possible the characterization and differentiation of ceramic pastes of different origin and to link their composition with local and extra-regional geology. We consider that the QEMSCAN and petrographic analysis provide complementary information, and its combined application is important to study the origin of ceramic materials and the manufacture of archaeological ceramics.

Keywords: QEMSCAN, petrographic analysis, archaeological pottery, Mendoza, Argentina.

\section{Introducción}

En este trabajo se integran y comparan los resultados obtenidos mediante la aplicación de dos técnicas analíticas utilizadas para el estudio de pastas cerámicas: análisis mineralógico automatizado por QEMSCAN (Quantitative Evaluation of Minerals by Scaning Electron Microscopy), y análisis petrográfico de secciones delgadas mediante microscopio de polarización óptica. El objetivo consistió en explorar el potencial de complementariedad entre una técnica que cuenta con una larga tradición en arqueología, cuyas fortalezas y limitaciones son ampliamente conocidas (petrografía por microscopía óptica), y una técnica que se presenta como una innovación para el estudio de pastas, cuya aplicación cuenta con escasos antecedentes en nuestra disciplina (QEMSCAN). Para ello, se aplicaron análisis de QEMSCAN a muestras de material cerámico arqueológico provenientes del Centro Oeste Argentino, que fueron estudiadas previamente en microscopio petrográfico. Los resultados obtenidos a partir del análisis mineralógico automatizado permitieron contrastar y profundizar las inferencias realizadas a partir de los estudios petrográficos (Frigolé et al. 2014; Frigolé 2017).

\subsection{Caso de estudio: escala espacial y temporal}

Los materiales cerámicos analizados fueron recuperados mediante recolecciones superficiales y excavaciones sistemáticas efectuadas en distintos sitios del sector noroeste de la provincia de Mendoza, en la región arqueológica del Centro Oeste Argentino (Fig. 1). Los sitios arqueológicos se ubican en tres unidades morfoestructurales: cordillera frontal, precordillera (tierras altas) y valles intermontanos (tierras bajas), que presentan condiciones ambientales particulares y se encuentran vinculados mediante quebradas que facilitan el acceso a cada ambiente (Figs. 1 y 2). 


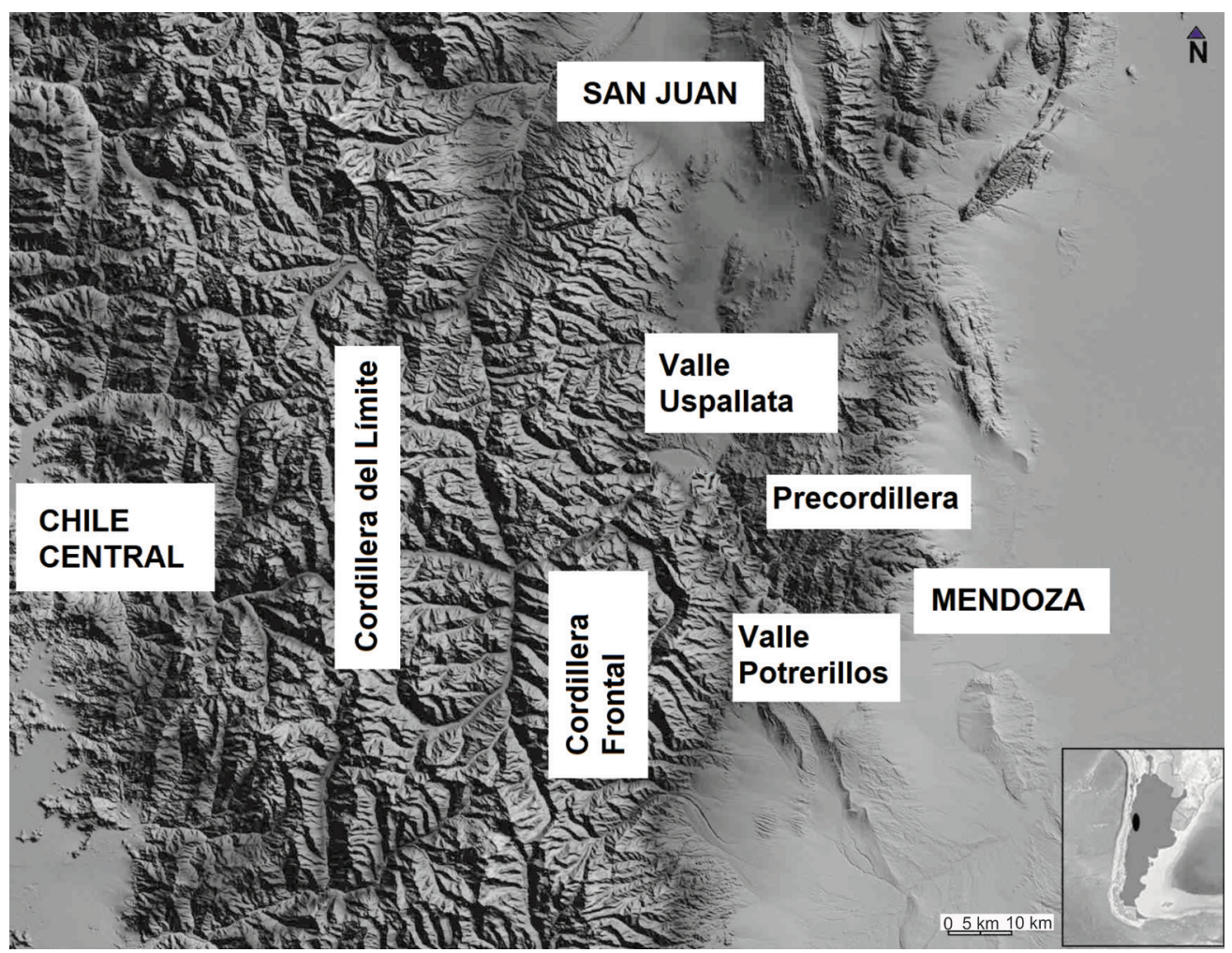

Figura 1. Área de estudio. Se observan la Cordillera Frontal (sitio La Manga), precordillera (sitio Agua de la Cueva) y valles (sitios Chanchería Oeste, San Ignacio, Casas 1 y 2).

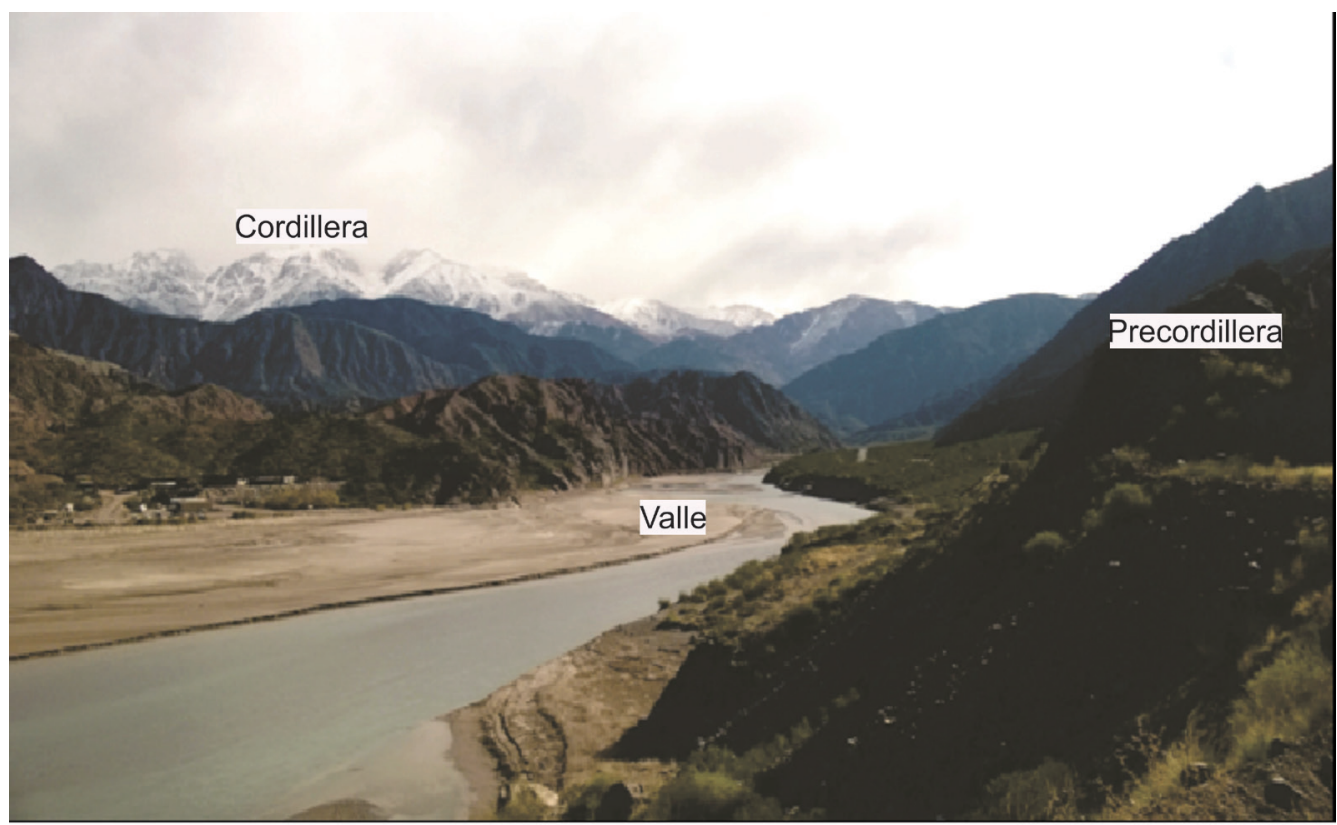

Figura 2. Vista de las tres unidades morfoestructurales en el valle de Potrerillos (NO de Mendoza, Argentina). 
El área resulta propicia para estudiar patrones de asentamiento que integraron ambientes altitudinales diversos y próximos entre sí (Durán y García 1989; Chiavazza y Cortegoso 2004; Cortegoso 2004, 2006) (Fig. 2). Por otro lado, posee una ubicación geográfica que es interesante para considerar vínculos y circulación de vasijas entre los diversos grupos sociales que habitaron en ambas vertientes de los Andes.

La cronología se definió a partir de la calibración y el modelado mediante estadística de Bayes de 10 fechados radiocarbónicos, el inicio se sitúa en 1490-1340 AP (con un 68\% de probabilidades) y su límite final en 950-780 AP (con un 68\% de probabilidades) (Frigolé 2017). El rango corresponde al período Medio y al inicio del Tardío de la Etapa Agroalfarera del Centro Oeste Argentino.

A partir de análisis petrográficos, mineralógicos (DRX) y químicos (FRX), aplicados a materiales cerámicos y muestras de potenciales materias primas (arenas, arcillas) (Frigolé 2017), se ha propuesto que durante dicho rango temporal, los grupos que ocuparon los ambientes del área de estudio habrían producido cerámica a nivel local (sensu Arnold 1985, 2006; Druc 2013) con mayor frecuencia en las tierras bajas de los valles y la trasladaron hacia tierras altas durante sus movimientos (Frigolé et al. 2014; Frigolé y Gasco 2016; Frigolé 2017). Con menor frecuencia, pudieron producir cerámica en tierras altas precordilleranas (Durán y García 1989; García 1994; Frigolé 2017) y trasladarla hacia los valles y sitio altos de la Cordillera Frontal (Frigolé 2017). Estas poblaciones habrían participado, además, en redes de intercambio interregional en donde circulaba cerámica de origen trasandino (García 1994; Cortegoso 2006; Frigolé et al. 2014; entre otros).

\section{Materiales y métodos}

Los materiales cerámicos han sido estudiados previamente mediante análisis petrográficos, DRX y FRX (Frigolé et al. 2014; Frigolé 2017). En este trabajo, retomamos parte de los resultados correspondientes al análisis petrográfico de las pastas cerámicas y su agrupación en familias y patrones, cuya caracterización fue comparada y complementada con los resultados obtenidos por QEMSCAN.

Se observaron y clasificaron en lupa binocular marca Nikkon (10x60x) las pastas de 502 tiestos cerámicos, que representan el 53\% de la muestra analizable ( $\mathrm{N}=943)$ (Frigolé 2017). Luego, se seleccionaron 90 fragmentos (18\% del total de muestras de pastas observadas en lupa) (Frigolé 2017) para el análisis petrográfico. Se utilizó un microscopio Leica DM750 P y un microscopio Enosa M-80-P2 acoplados a cámaras digitales. Se agruparon las muestras en grupos generales de familias de pastas, de acuerdo a la naturaleza geológica de las inclusiones ${ }^{1}$ (sensu Falabella et al. 2002; Sanhueza 2004), y en subgrupos de patrones de pastas teniendo en cuenta los demás atributos de las inclusiones y matriz (sensu Falabella et al. 2002; Sanhueza 2004; Cremonte y Bugliani 2006-2009; Druc y Chávez 2014; entre otros).

Los criterios para la discriminación en patrones se basaron, además de la composición mineral de las mismas (familias), en la granulometría y abundancia de inclusiones, a las que se sumaron estados de atributos referidos al aspecto general de la matriz, características de las inclusiones (descripción, forma y distribución), de las cavidades y textura de la pasta (Cremonte y Bugliani 2006-2009; Sanhueza 2004). Los tamaños se clasificaron en rangos (Orton et al. 1993; escala de Wentworth modificado de Folk 1965). Los porcentajes de abundancia, forma y distribución de las inclusiones se determinaron por comparación con diagramas para estimación de densidad (Mathew et al. 1991) y escalas de esfericidad y de distribución (Barraclough 1992).

Del total de fragmentos analizados por petrografía, se seleccionó una submuestra de 21 fragmentos cerámicos para el análisis de QEMSCAN. Los análisis se realizaron en la Unidad de Equipamiento Científico MAINI (UCN), utilizando un modelo E430 de QEMSCAN, un microscopio electrónico de barrido que ha sido modificado, tanto en sus componentes físicos 


\section{Lista de Minerales}

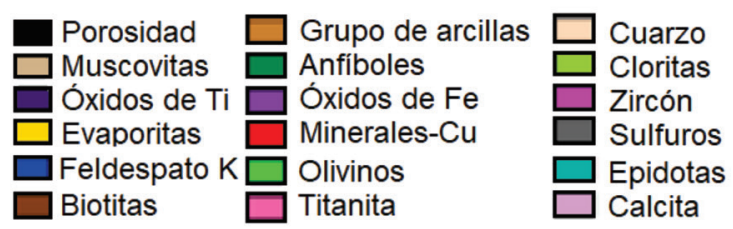

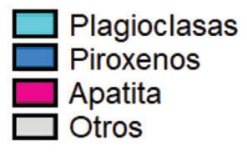

Figura 3. Lista de minerales seleccionados en el software iDiscover para el estudio de fragmentos cerámicos. Esta lista es la guía para interpretar los resultados entregados como mapas mineralógicos.

y mecánicos como en su software. Se trata de un sistema configurado para medir la variabilidad mineralógica sobre la base de la información química en escala micrométrica, originalmente desarollado para proporcionar datos mineralógicos rápidos, automatizados y totalmente cuantitativos (Knappett et al. 2011). Los análisis de QEMSCAN han sido aplicados con éxito a cerámicas arqueológicas del Norte de Chile (Menzies et al. 2015). La metodología basada en QEMSCAN que se presenta aquí corresponde a un proyecto de tesis de magíster (Riera-Soto 2019), que busca estudiar la composición y preservación de materiales cerámicos mediante dicha técnica.

Los fragmentos cerámicos fueron montados en briquetas de resina Epofix, para luego ser cortadas y pulidas. La identificación, cuantificación y mapeo de fases inorgánicas se realizó mediante la combinación de emisiones de electrones retro-dispersados y rayos X (Pirrie et al. 2004). Los datos obtenidos de este proceso fueron clasificados en una lista composicional jerárquica y descendente conocida como «lista SIP». El resultado de análisis son imágenes pixeladas en 2D y en falso color, procesados con iDiscover. Este software permite la confección de filtros personalizados para cuantificar abundancias minerales representadas en mapas mineralógicos, asociaciones entre fases inorgánicas, clasificar partículas de acuerdo a criterios de forma, tamańo, textura, entre otros.

Para este estudio se consideraron veinte categorías, entre minerales y grupos minerales, además de la porosidad y la categoría de "otros», la cual agrupó todos los demás casos de minerales que son detectados por QEMSCAN (Fig. 3). La descripción e importancia de estos minerales para el análisis petrográfico de cerámica se encuentra descrito en Riera-Soto (2019).

Con la finalidad de explorar el comportamiento de las muestras, ordenar el conjunto para facilitar la descripción de los resultados de QEMSCAN, y observar si estos guardan coherencia con los agrupamientos de pastas por petrografía, se aplicaron análisis de estadística multivariada sobre los valores relativos de las concentraciones de los minerales obtenidos por QEMSCAN. Se realizaron Análisis de Conglomerados (AC), aplicando el método de Pares Agrupados con distancia euclidiana, y Análisis de Componentes Principales (ACP), previa estandarización de los mismos a través de logaritmo de base 10. Los análisis estadísticos se llevaron a cabo con el software PAST (versión 3.06) (Hammer et al. 2001).

\section{Síntesis de resultados de petrografía y QEMSCAN}

A continuación, presentamos una síntesis de la caracterización de la composición petrográfica y mineralógica por cada familia de pasta (Frigolé 2017), integrando los resultados obtenidos por el análisis en microscopio de polarización y QEMSCAN.

\subsection{Familia de pastas volcánicas (V)}

Corresponde a cerámica de cocción reductora u oxidante incompleta (Moyano y Frigolé 2013), con superficies alisadas y pulidas y con decoraciones plásticas (incisiones en chevrones). Estos tipos cerámicos remiten a la tradición Agrelo-Calingasta (c. 500-1000 d.C) de distribución regional en 


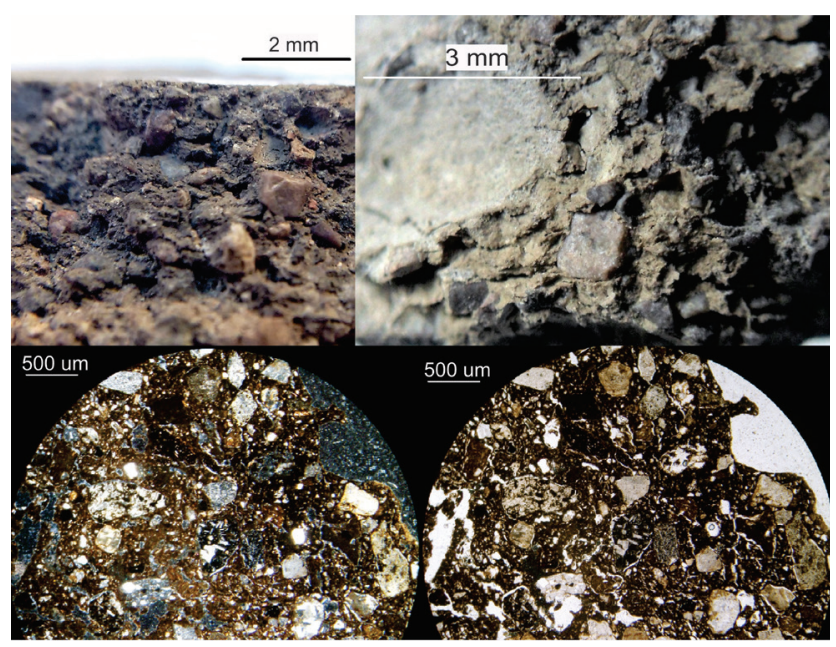

Figura 4. Arriba, fotografias en lupa (10x$60 x)$ de muestras de la familia V. Abajo, fotomicrografias de una muestra de la familia V (patrón V.2) (izquierda en XPL, derecha en PPL).

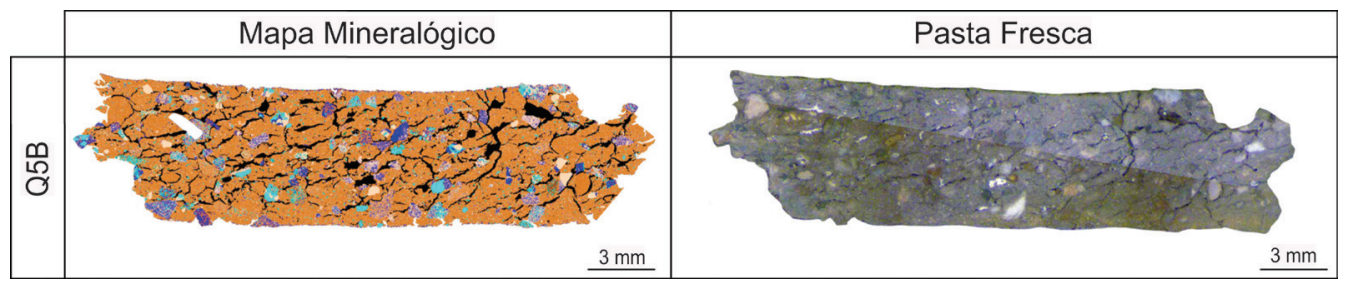

Figura 5. Mapa mineralógico de la muestra Q5B, representativa de la familia Vy del patrón V.1, del sitio Agua de la Cueva (Precordillera). A la derecha, briqueta de la muestra analizada. Referencia de color Fig. 3.

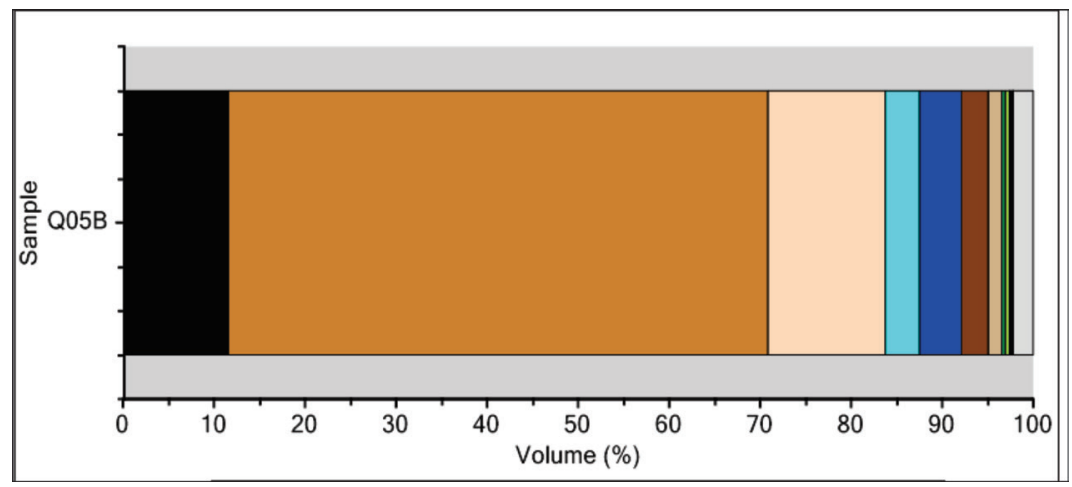

Figura 6. Gráfico de proporciones de minerales presentes en la muestra Q5B y referencias de color por mineral. Referencia de color Fig. 3.

el Centro Oeste Argentino, más específicamente del norte y centro de Mendoza y sur de San Juan (Canals Frau 1956; Gambier 2000).

A partir de los resultados petrográficos, estas pastas se caracterizaron como porosas, intermedias y gruesas, con abundante material volcánico (principalmente andesita, dacita y en menor medida basalto y riolita) (Frigolé 2017; Frigolé et al. 2014) (Fig. 4).

Los datos de la composición mineralógica obtenidos por QEMSCAN para las muestras de esta familia, indican que poseen un predominio de cuarzo, en menores porcentajes plagioclasa y feldespato potásico (en proporciones similares), y escasas proporciones de muscovita (Figs. 5 y 6). En algunos casos se destaca que dichos minerales forman parte de la composición de los litoclastos, 


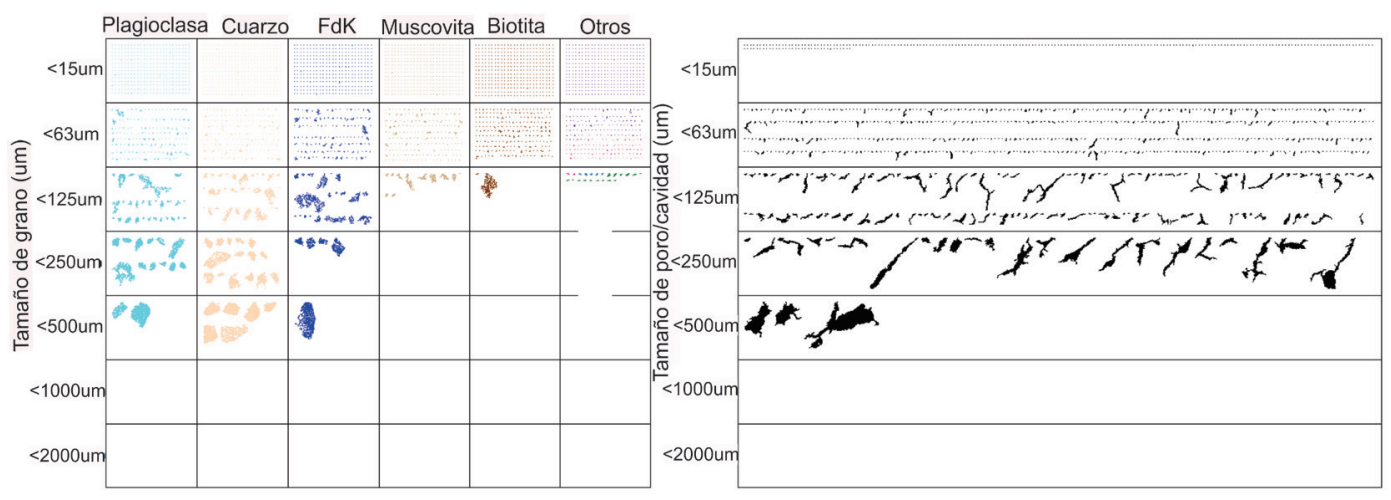

Figura 7. Relaciones gráficas de tamaño y forma con tipos de minerales y de cavidades de la muestra Q5B.

la que fue analizada mediante la observación petrográfica, si bien puede también observarse en los mapas mineralógicos obtenidos por QEMSCAN (v.g. Fig. 5).

Dentro de esta familia se discriminaron dos patrones por petrografía (V.1 y V.2), según la densidad y granulometría de las inclusiones, y la abundancia de cristaloclastos ${ }^{2}$. El patrón V.2 presenta pastas con inclusiones líticas en general más gruesas y abundantes y con mayores proporciones de cristaloclastos que en V.1. Algunas muestras de V.2 poseen mayor abundancia de fragmentos muy finos de cuarzo, plagioclasa y roca volcánica, posiblemente desagregados de las inclusiones de mayor tamaño (Frigolé 2017) (fotomicrografías de Fig. 4).

$\mathrm{El}$ análisis por QEMSCAN también detectó variabilidad entre las muestras de esta familia, coherente con los subgrupos de patrones de pasta. Estas diferencias se observaron en relación a la abundancia de plagioclasa, feldespato potásico (más abundantes en V.2) y en las proporciones de arcillas y poros. Se destaca que los gráficos obtenidos mediante el análisis de QEMSCAN que relacionan abundancia y formas de las cavidades y de minerales (Fig. 7) permitieron profundizar la caracterización de ambos patrones.

\subsection{Familia de pasta con abundantes minerales félsicos (Q-PL)}

Estas pastas se hallan asociadas casi en su totalidad a cerámica alisada y de cocción reductora u oxidante incompleta (Moyano y Frigolé 2013), en algunos casos con estriados e incisos indeterminados (Frigolé 2017). Estos tipos de decoraciones plásticas corresponden también a estilos del COA, más específicamente a la tradición Agrelo-Calingasta (Canals Frau 1956; Gambier 2000). Uno de los tiestos cuya pasta se incluyó en esta familia presenta una superficie con cubierta ${ }^{3}$ roja y alisada, cuya adscripción tipológica resulta dudosa.

Las pastas de este grupo se caracterizan por ser finas y porosas con abundantes minerales félsicos (plagioclasas y cuarzos) (Figs. 8 y 9). Además, presentan una mezcla de litoclastos minoritarios de origen volcánico (en proporciones escasas y moderadas), sedimentario, metamórfico y plutónico (en proporciones trazas), que son en general de tamaños más finos y escasos que los cristaloclastos (Frigolé 2017; Frigolé et al. 2014).

Los datos de la composición mineral analizada por QEMSCAN indicaron a nivel general, para esta familia, abundancia de plagioclasa, y en menor proporción, cuarzo y biotita. Posee, además, muy bajos porcentajes de feldespato y mayor cantidad de muscovita en relación a las pastas volcánicas (Fig. 10).

Las variaciones observadas mediante el análisis petrográfico en relación a la densidad y granulometría de los minerales félsicos determinaron tres patrones de pasta al interior de esta familia (Q-PL.1, Q-PL.2 y Q-PL.3) (Frigolé 2017). Estas diferencias también se evidenciaron 

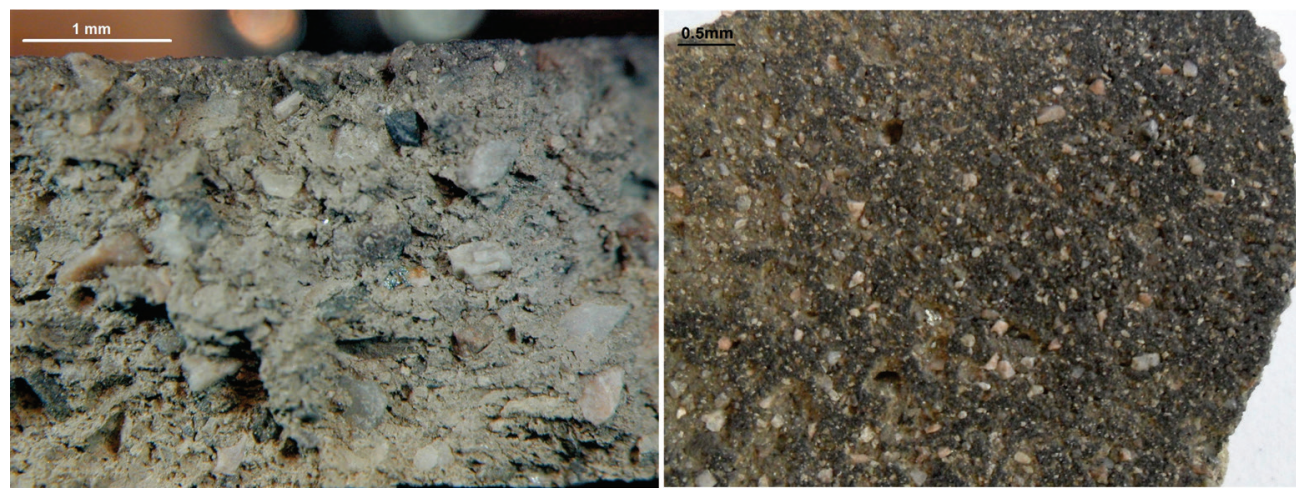

Figura 8. Fotografias en lupa $(10 x-60 x)$ de muestras de la familia Q-PL.
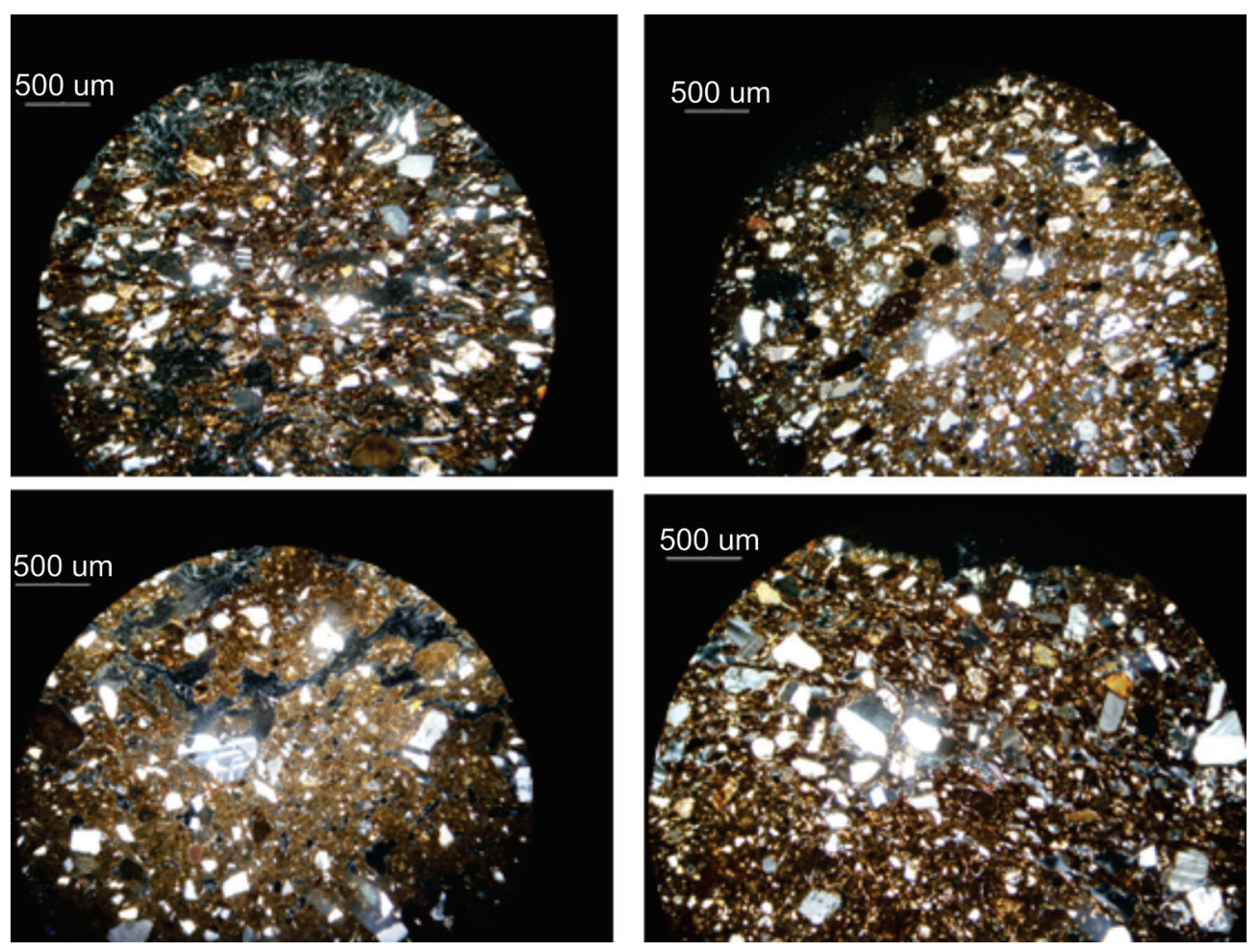

Figura 9. Fotomicrografias de pastas correspondientes a la familia Q-PL en XPL.

en los resultados del análisis por QEMSCAN, dado que se detectaron muestras con mayor proporción de plagioclasas, lo que se condice con la discriminación en patrones por petrografía según la abundancia de minerales félsicos (Fig. 11).

Los resultados de QEMSCAN evidenciaron que la pasta del fragmento con cubierta roja posee mayores proporciones de cuarzo y de feldespato potásico (este último en cantidad moderada) que el resto de las muestras de esta familia, además se detectó abundancia de minerales muy finos de clorita distribuidos en el sector de la cubierta (Fig. 12), que podrían formar parte de su composición. 


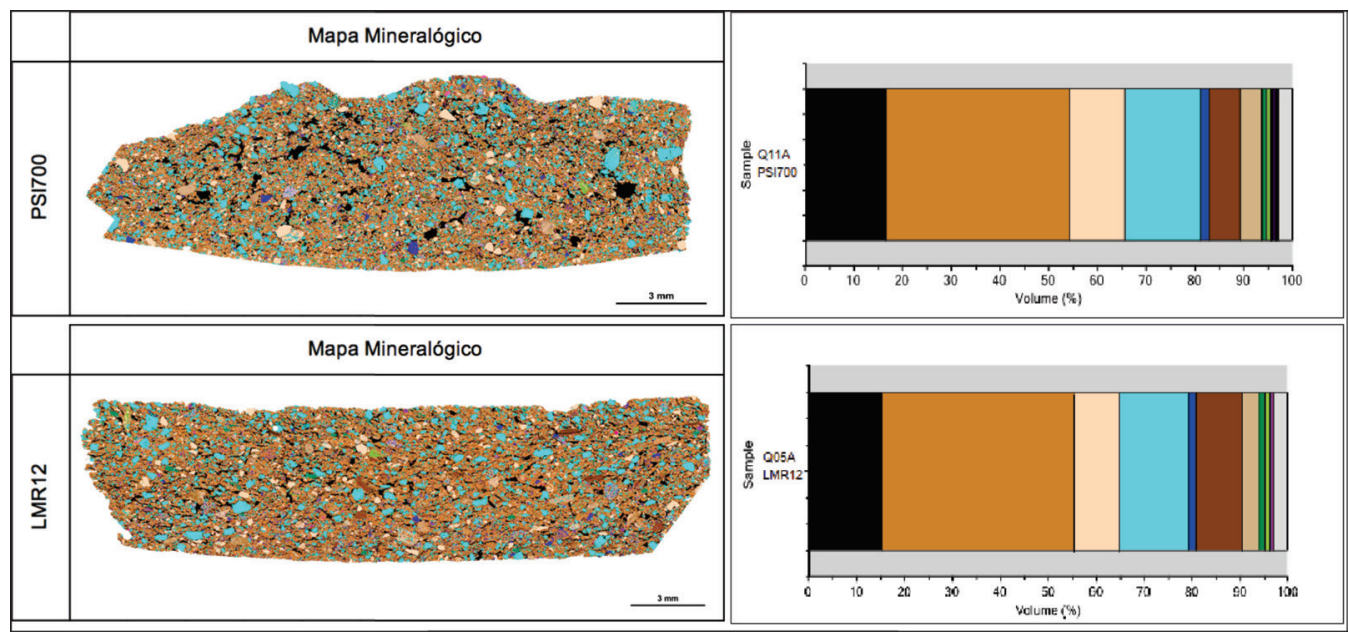

Figura 10. Mapas mineralógicos y gráficos de porcentajes de los minerales detectados por QEMSCAN. Las muestras corresponden a familia Q-PL (patrón Q-PL1). Arriba, muestra del valle de Potrerillos (PSI700-Q11A). Abajo, muestra de un sitio de la Cordillera Frontal (LMR12-Q5A). Referencia de color Fig. 3.
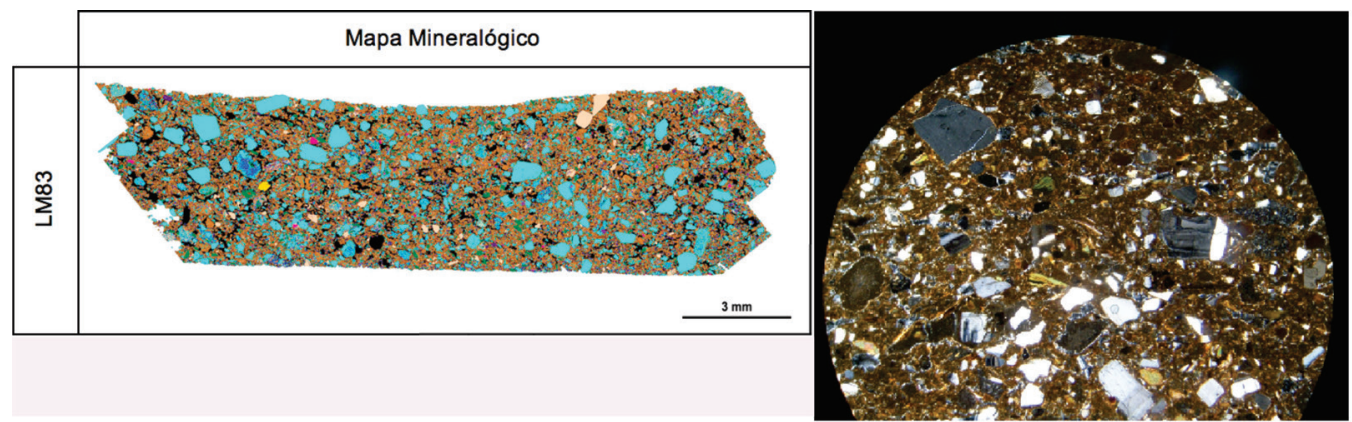

Figura 11. A la izquierda, mapa mineralógico de la muestra LM83-Q16 de la familia Q-PL (patrón Q-PL.2, con mayor abundancia de plagioclasas). A la derecha, fotomicrografia de la sección delgada en XPL de la misma muestra. Referencia de color Fig. 3.

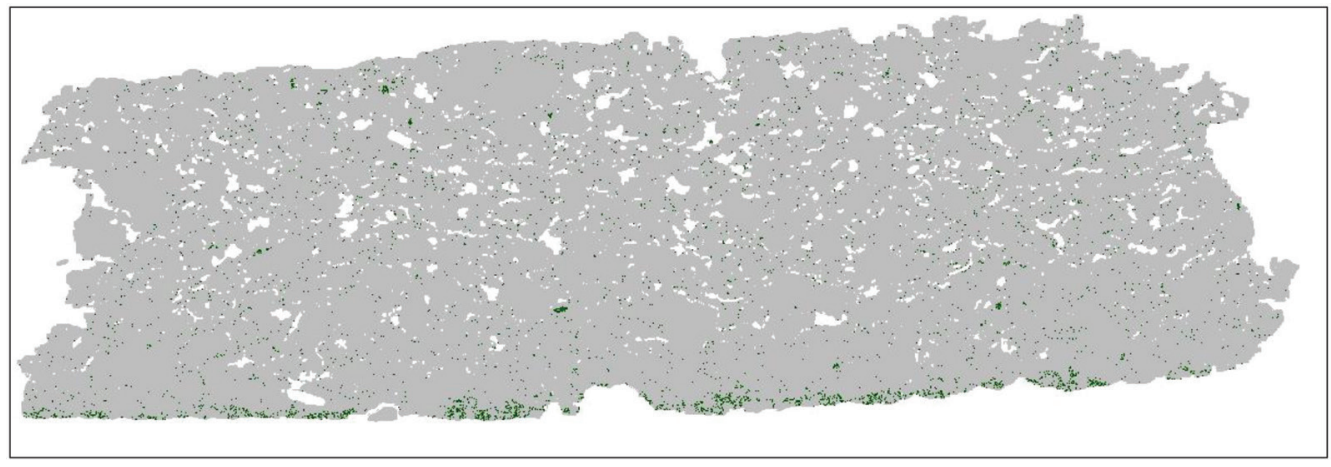

Figura 12. Mapa mineralógico correspondiente a la clorita. Se observan en verde, en la superficie externa los minerales de clorita del fragmento con cubierta rojiza. 

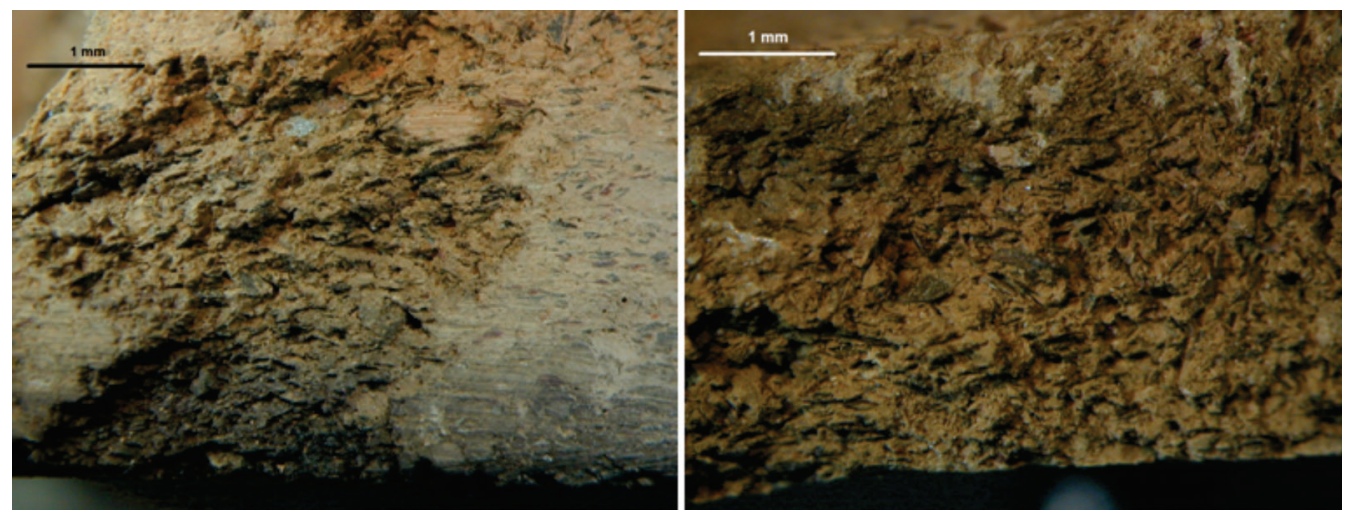

Figura 13. Imágenes de cortes frescos del conjunto de pastas correspondiente a la familia MM. A la izquierda, fragmento de tierras bajas del valle de Uspallata (sitio Chancheria Oeste). A la derecha, fragmento de tierras altas precordilleranas (sitio Agua de la Cueva).
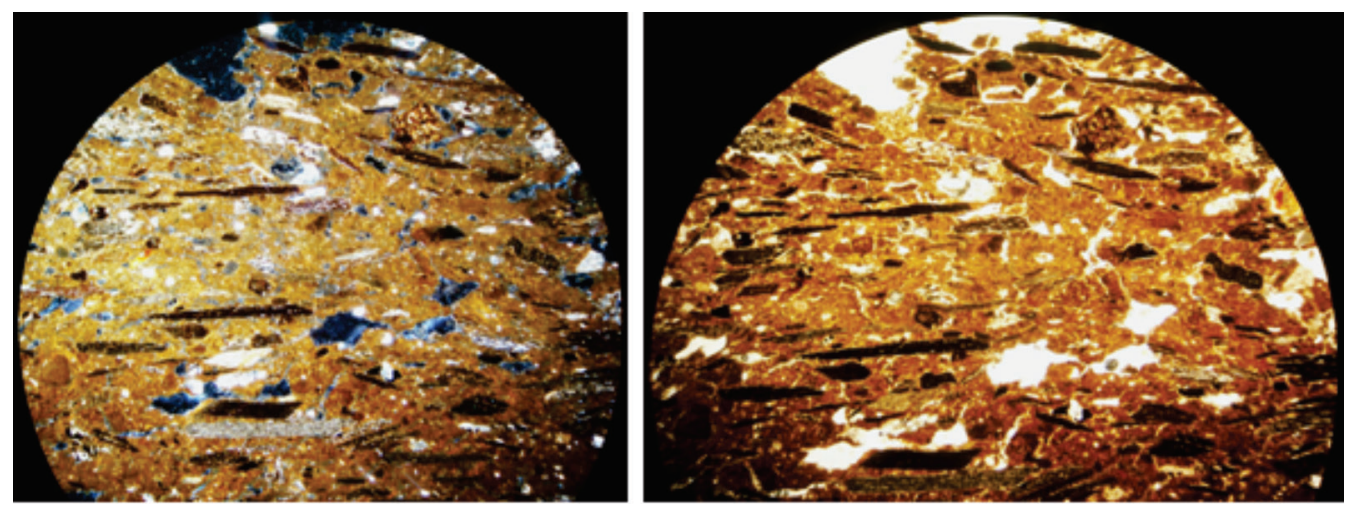

Figura 14. Fotomicrografias en XPL (a la izquierda) y en PPL (a la derecha) de fragmento proveniente de un sitio de la Cordillera Frontal (La Manga). Los fragmentos elongados en dirección horizontal son de metamorfitas (filitas y pizarras). A la derecha en PPL, la coloración de la matriz se observa rojiza.

\subsection{Familia de pastas con abundante material metamórfico de bajo grado (MM)}

Corresponde en su mayoría a cerámica oxidada, con excepción de escasos tiestos que presentaron pastas grises, superficies principalmente erosionadas, con cubiertas desleídas (posiblemente engobes ${ }^{4}$ ) y en algunos casos alisadas. La familia MM se caracteriza por presentar pastas densas, gruesas y laminares, con abundante material metamórfico (esquistos, filitas y pizarras) (Figs. 13 y 14) que se observan como tablillas elongadas, en muchos casos ordenadas según una dirección preferencial, que coincide con la fisilidad de los minerales micáceos (Fig. 14) (Frigolé y Gasco 2016; Frigolé 2017). Esta disposición de los minerales también se observó en los mapas obtenidos por QEMSCAN (Fig. 15).

Teniendo en cuenta la abundancia y que en algunos casos los litoclastos se observan muy angulosos definimos dos patrones en esta familia por petrografía. Pensamos que es posible que las pastas hayan sido preparadas tanto con arcillas y barros sin agregado (patrón MM.1) (Fig. 14), como con agregados de arenas más gruesas o incluso de rocas metamórficas (foliadas) molidas (MM.2) (Frigolé 2017).

Los resultados de QEMSCAN evidencian abundancia de muscovita, biotita y cuarzos, en proporciones similares (Fig. 15), lo que se condice con las observaciones petrográficas, dado que la mayor parte de los esquistos y filitas presentaron una composición micácea. En el análisis 


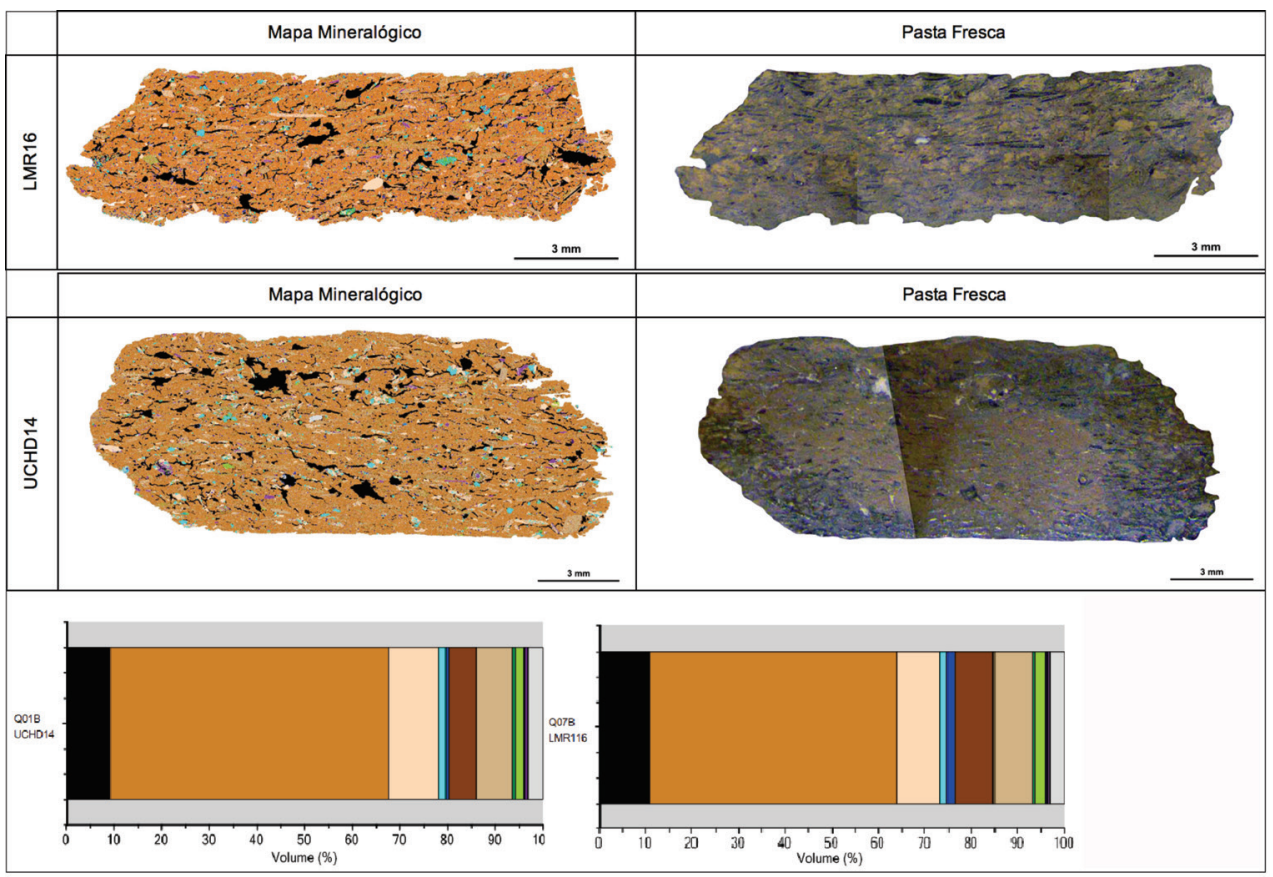

Figura 15. Mapas mineralógicos (arriba, izquierda), briquetas (arriba, derecha) y gráficos de proporciones (abajo). Corresponden a las muestras LMR16-Q7B (Cordillera, La Manga) y UCHD14-Q1B (valle de Uspallata, Chanchería). Referencia de color Fig. 3

petrográfico se identificaron también esquistos con alternancia de bandas de cuarzo y micas y pizarras compuestas de cuarzo y biotita.

La abundancia de muscovita, presencia de clorita y proporciones trazas de plagioclasas y feldespato diferencian claramente este grupo de las pastas con abundantes minerales félsicos y de las volcánicas. Además, se observó que los porcentajes de arcilla (proporción de la matriz) son altos en relación a la densidad de minerales (Fig. 15).

\subsection{Familia de pastas con granito (GR)}

Se caracteriza por poseer pastas finas y porosas, con presencia de granito y ausencia de materiales volcánicos, metamórficos y sedimentarios (Frigolé et al. 2014; Frigolé 2017) (Fig. 16). Se encuentra asociada a cerámica bruñida negra y con superficies pulidas y cubiertas rojas, que remiten a estilos trasandinos. La cerámica bruñida negra presenta características tipológicas similares a los tipos El Molle del Norte Chico chileno (Cornely 1958; Niemeyer et al. 1989; entre otros).

Los resultados de QEMSCAN indicaron para la misma muestra abundantes porcentajes de clorita (21\%, los más altos de todo el conjunto), presentes mayoritariamente en la composición de la matriz (Figs. 17 y 18), lo que la diferencia significativamente del resto de las familias. Además, presentó la porosidad más baja de todo el conjunto analizado y altos porcentajes de feldespato potásico (Fig. 18).

\section{Resultados de los análisis de agrupamiento (AC) y de componentes principales (ACP)}

Del análisis de agrupamiento aplicado a los valores relativos de las concentraciones de los minerales obtenidos por QEMSCAN (Tabla 1), se obtuvo un dendograma (Fig. 19) en el que pueden 


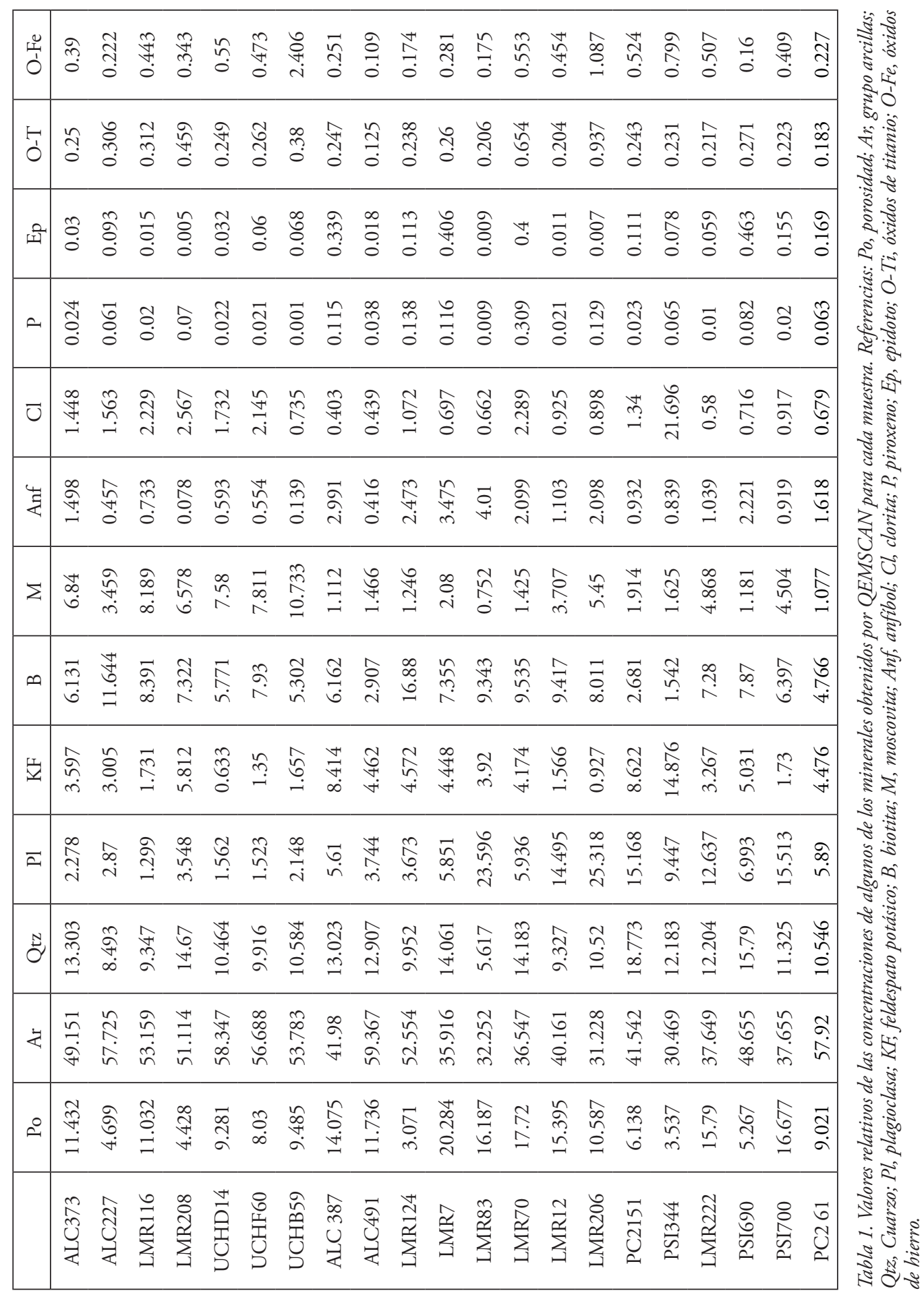




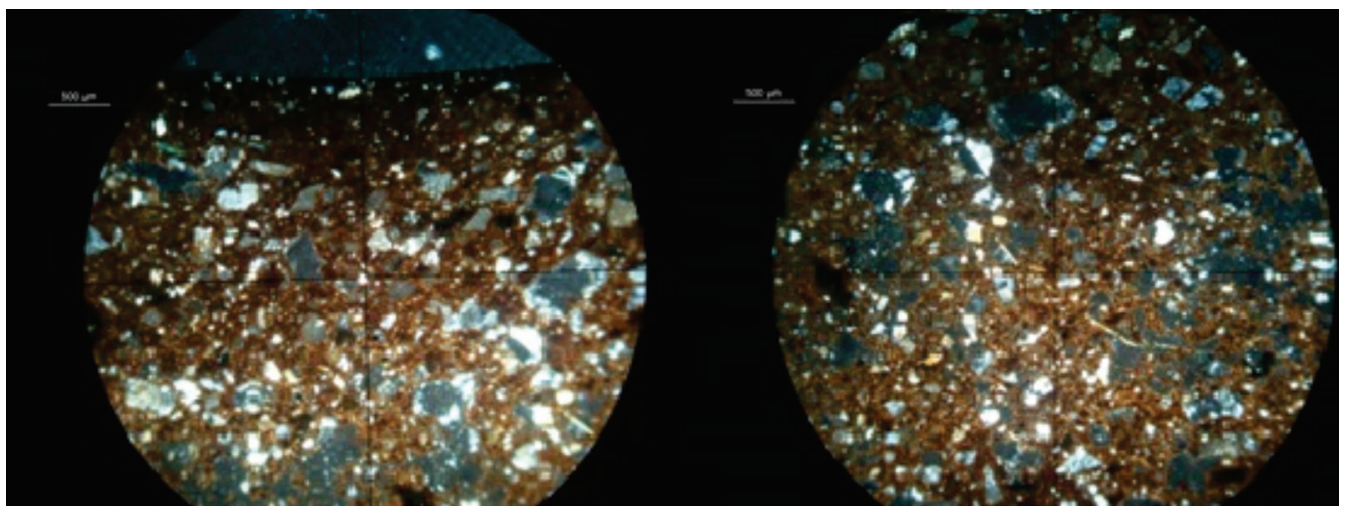

Figura 16. Fotomicrografía en XPL de la sección delgada correspondiente a la muestra de cerámica bruñida negra.

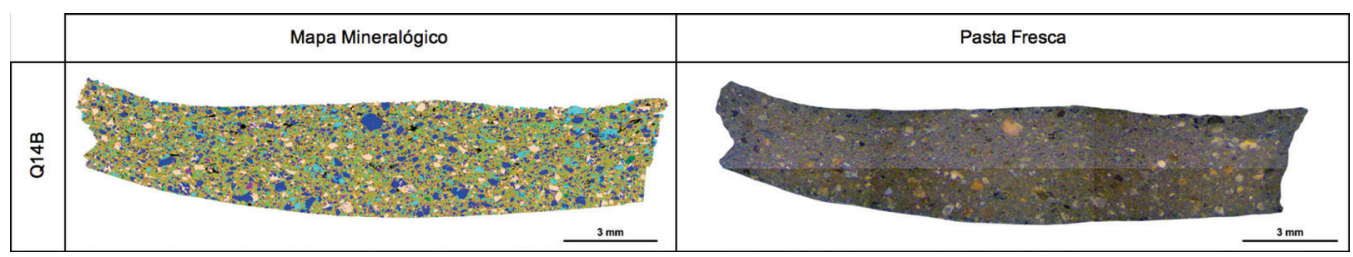

Figura 17. Mapa mineralógico (izquierda, se observan en verde los minerales de clorita) e imagen de la sección analizada (derecha) correspondiente a la muestra de la familia GR. Referencia de color Fig. 3.

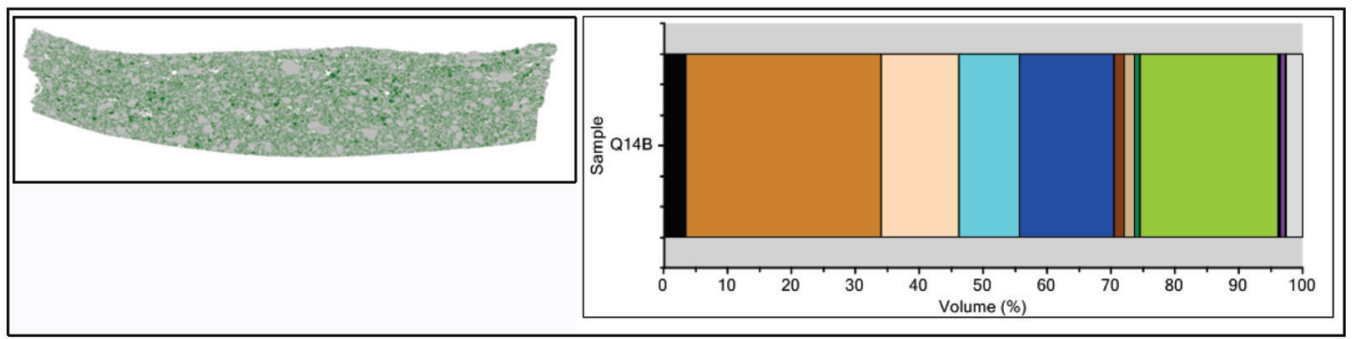

Figura 18. A la izquierda, mapa mineralógico correspondiente a la clorita, en verde se observa su abundancia y su distribución principalmente en la matriz. A la derecha, gráfico de proporciones, se destaca los altos porcentajes de clorita (en verde).

discriminarse tres conglomerados que en general resultan coherentes con los grupos definidos por petrografía, salvo para el caso de la muestra PC2151 (familia Q-PL, fragmento con cubierta roja) que se une a mayor distancia con el grupo de la familia $\mathrm{V}$.

Los agrupamientos poseen variabilidad interna, ya que se agrupan a distancias cada vez mayores. La muestra de la familia GR, que remite a tradiciones de procedencia extra regional no se agrupa con ninguno de los conglomerados (Fig. 19).

Los resultados del análisis de ACP permitieron explorar las posibles agrupaciones de las muestras, cuya disposición en el espacio multivariado, conformó tres grupos composicionales, que se observan en el diagrama de dispersión (Fig. 20). En este se diferencian las tres familias de pastas delimitadas por elipses que representan intervalos de confianza de $90 \%$ para la inclusión de las muestras en cada grupo. Los tres grupos guardan coherencia con los grupos de familias de pastas conformadas a partir del análisis petrográfico. 


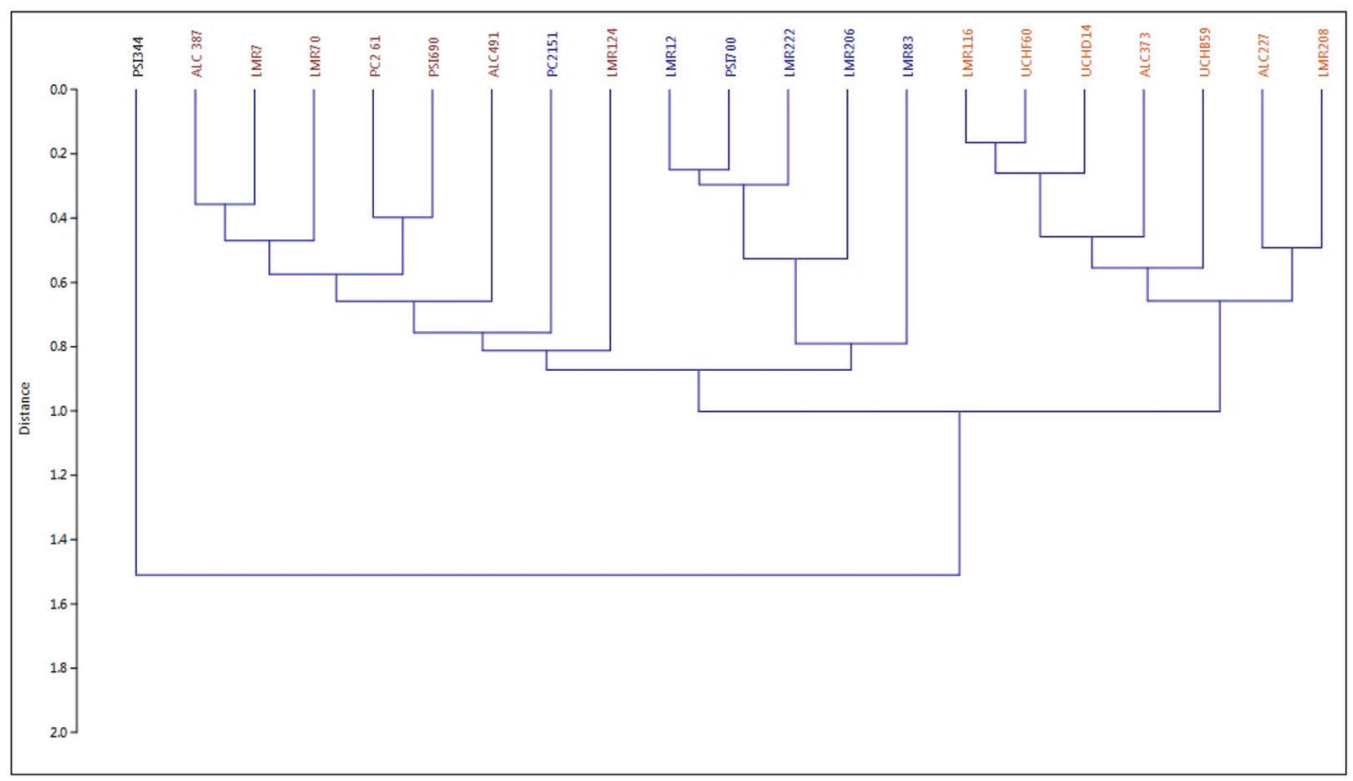

Figura 19. Dendograma resultante de la aplicación del AC a los datos obtenidos por QEMSCAN. Se observa en negro el código del fragmento correspondiente a la familia $G R$, en marrón los códigos de la familia $V$, en azul, la familia Q-PL, y en naranja la familia $M M$.

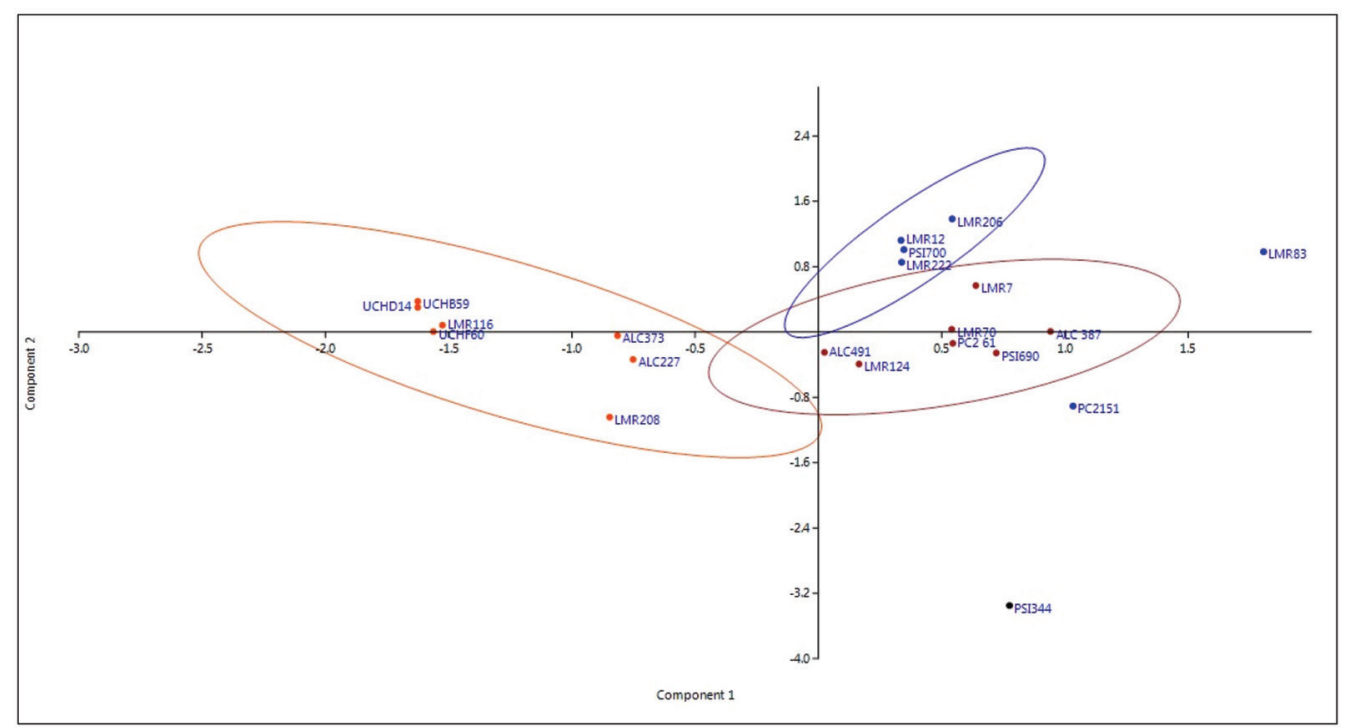

Figura 20. Diagrama de dispersión obtenido mediante ACP. Las elipses representan intervalos de confianza de 90\% para la inclusión de las muestras en cada grupo. Se consignan los códigos y números de cada muestra. Azul: familia Q-PL, marrón: familia Vy naranja: familia MM. Los componentes 1 y 2 explican el 62.8\% de la varianza (componente 1: 36.61\%; componente 2: 26.19\%). 
El grupo que incluye a las muestras de pastas metamórficas (elipse naranja), a la izquierda del eje, es el más claramente definido. Mientras que los grupos que corresponden a la familia $\mathrm{V}$ (elipse marrón) y la familia Q-PL (elipse azul) presentan mayores similitudes entre sí (Fig. 20). Es probable que hubiera sido más difícil encontrar las diferencias entre las familias V y QPL de no haber conocido previamente sus pastas por petrografía, aunque una vez conocido el grupo su discriminación es posible.

Las muestras PC2151 y LM83 no se incluyen en ninguna elipse, por lo que presentarían una composición mineralógica diferente al resto de las muestras de la familia de pastas Q-PL, a las que habían sido atribuidas por petrografía. La muestra LM83 se separa del resto por poseer mayor porcentaje de plagioclasa (integra el patrón Q-PL.3 que es el que presenta mayor densidad de plagioclasa) y de anfíbol, este último presenta mayor escasez en el resto de la familia PL. Mientras que la muestra PC2151 que corresponde al tiesto con cubierta roja, posee más cuarzo y feldespato potásico, y se acerca más al conjunto de pastas volcánicas, lo que se observa también en el dendograma obtenido por AC, donde la muestra se incluye en el cluster que agrupa a la familia V (Fig. 19). Por otro lado, la muestra a la que atribuimos una procedencia extra-regional que corresponde al tiesto de superficies bruñidas negras (PSI344-Q14B), se observa como un outsider, es la que más se aleja del resto del conjunto principalmente por presentar altos porcentajes de clorita (Fig. 20).

\section{Discusión y consideraciones finales}

Los datos obtenidos por QEMSCAN permitieron profundizar la caracterización mineralógica obtenida mediante el análisis en el microscopio, dado que dicha técnica permite la cuantificación de una gama amplia de minerales en toda la sección para tamaños muy finos que forman parte de la matriz, cuya identificación precisa en el análisis por microscopio de polarización puede presentar dificultades. Al mismo tiempo, el análisis petrográfico permitió precisar en qué medida la abundancia de minerales que detecta QEMSCAN pueden considerarse como cristaloclastos (conformando la fracción no plástica), o son parte de la composición de los litoclastos. Si bien esto podría observarse en los mapas mineralógicos, en nuestro caso, QEMSCAN reconoció de manera automática minerales, más no los atributos petrográficos. Destacamos entonces la necesidad de generar mejores filtros para que QEMSCAN pueda identificar automáticamente los litoclastos, los cuales son reconocidos con facilidad al microscopio óptico. Para este estudio, los litoclastos observados en los mapas mineralógicos fueron reconocidos visualmente, donde el análisis previo en microscopio óptico fue fundamental para poder corroborar la composición de los litoclastos. Mejorando los filtros se podrá conocer automáticamente que porcentaje de una composición mineral es parte de los litoclastos y de los cristaloclastos por separado.

La información que brinda el análisis de QEMSCAN en relación a la porosidad, porcentajes de arcilla, proporción y forma de cavidades y minerales permitieron completar la diferenciación en patrones de pasta realizada por petrografía. En relación a las familias de pasta, observamos que los datos obtenidos por QEMSCAN permitieron discriminar en general los mismos grupos de pastas que se habían conformado por observación petrográfica, con excepción de algunas muestras que deben ser reevaluadas.

A partir del análisis estadístico de los datos de QEMSCAN, observamos que, tanto en el AC como en el ACP, los agrupamientos que corresponden a las familias V y Q-PL son las que muestran mayores similitudes entre sí. Presentan proporciones abundantes y similares de cuarzo, y se diferencian principalmente por los altos porcentajes de plagioclasas presentes en la familia Q-PL. En menor grado, se diferencian por las proporciones de feldespato potásico (mayores en V) y muscovita (mayores en Q-PL). Si bien es posible diferenciar ambas familias mediante la aplicación de QEMSCAN, consideramos que el análisis petrográfico permitió una discriminación más clara al evidenciar además una mayor abundancia de inclusiones líticas volcánicas en V. 
A partir de estudios previos que consistieron en análisis petrográficos (Frigolé et al. 2014; Frigolé 2017), químicos (FRX) y de difracción de rayos X, aplicados tanto a los materiales cerámicos como a potenciales materias primas (Frigolé 2017), se ha propuesto que las áreas de proveniencia de ambas familias corresponden a distintos sectores cercanos de los valles que comparten los mismos marcos geológicos, en donde se ubican la mayor parte de los sitios (Frigolé et al. 2014; Frigolé 2017). Ambas familias presentan cantidades apreciables de litoclastos volcánicos, si bien estos son más abundantes en la familia $\mathrm{V}$ y los minerales félsicos lo son para la familia Q-PLG, y corresponden a tipos cerámicos de la misma tradición local (Agrelo-Calingasta). Teniendo en cuenta lo dicho, es esperable que guarden una mayor similitud entre sí, que, con el resto de las familias, como lo evidencia el análisis estadístico de los resultados de QEMSCAN.

El grupo que corresponde a la familia de pastas metamórficas se diferenció significativamente de la familia volcánica y de minerales félsicos, en este caso tanto los resultados de QEMSCAN, como los petrográficos discriminaron claramente las mismas muestras. Los análisis de QEMSCAN permitieron diferenciar esta familia principalmente por sus altos porcentajes de mica muscovita y biotita, los análisis petrográficos la diferenciaron por presentar abundante material metamórfico de bajo grado, compuesto principalmente por muscovita, biotita y cuarzo.

Por otro lado, los resultados de QEMSCAN obtenidos para la muestra que corresponde a la familia de pastas con granito (GR), permitieron reforzar la hipótesis de su procedencia extra regional (Frigolé et al. 2014; Frigolé 2017), y vincular su composición con los marcos geológicos del Norte Chico chileno, región a la que remite el estilo de la cerámica analizada (Complejo El Molle), lo que no fue posible a partir de la información del análisis petrográfico.

Si bien los resultados del análisis petrográfico permitieron vincular el resto de las familias con las formaciones geológicas presentes en el área de estudio y diferenciaron significativamente las pastas de la familia GR del resto de las muestras, no fue posible descartar a partir de dichos resultados la vinculación de estas pastas con las formaciones geológicas locales, específicamente las que se ubican en la Cordillera Frontal (Folguera et al. 2004). Los análisis de QEMSCAN determinaron para la muestra de pastas graníticas proporciones altas de clorita (21\%), presentes sobre todo en la matriz, mientras que en el resto de los fragmentos analizados la proporción de clorita oscila entre el 0 y $2 \%$. Si tenemos en cuenta que la clorita es producto de la alteración hidrotermal de las biotitas y otros minerales ferromagnesianos (Schwartz 1958), una abundancia de clorita podría ser esperable en los marcos geólogicos del Norte Chico chileno, donde tuvieron lugar procesos hidrotermales que durante el Mio-Plioceno, generaron cambios mineralógicos en las biotitas de las rocas presentes en las formaciones de dicha región (Winocur et al. 2014; Winocur et al. 2015). Por lo que los resultados de QEMSCAN permitieron asociar la composición mineral de esta cerámica a la geología de la región a la que remiten las características tipológicas del fragmento (complejo El Molle).

Destacamos que en el resto de las muestras QEMSCAN identificó proporciones moderadas o abundantes de biotita y ausencia o trazas de clorita. Si consideramos que en trabajos previos (Frigolé et al. 2014; Frigolé 2017; entre otros) las áreas de proveniencia de dichos materiales han sido atribuidas a las distintas unidades geomorfológicas del área de estudio en la vertiente oriental de Los Andes, podría pensarse que la abundancia de clorita podría ser un indicador con potencial para discriminar muestras de ambos lados de la cordillera, al menos entre el Norte Chico y el sector norte de Mendoza. Para reforzar esta idea, será necesario un análisis aplicado a un mayor número de muestras de estilos trasandinos.

En este sentido, la posibilidad de cuantificar con precisión minerales muy finos que conforman la matriz de las pastas por QEMSCAN puede resultar de fundamental importancia para discriminar pastas de procedencia diversa y vincular su composición a marcos geológicos presentes en escalas extrarregionales.

En síntesis, la información obtenida mediante la aplicación de QEMSCAN permitió profundizar la caracterización de las familias de pasta realizada previamente por petrografía, precisando 
sus diferencias y similitudes a nivel mineralógico. Esta técnica brinda información valiosa para discriminar pastas de distinta procedencia, ya que permite la detección precisa y automática de minerales muy finos que componen la arcilla, que por su tamańo y abundancia (trazas) presentan dificultades en su identificación por microscopio petrográfico.

En nuestro caso de estudio, los resultados obtenidos por el análisis automatizado guardan coherencia con los resultados del análisis petrográfico, y podría decirse que a partir de la aplicación de ambas técnicas se alcanzaron resultados similares. Sin embargo, enfatizamos que su aplicación conjunta hace posible una mejor contextualización de los datos obtenidos por cada una de ellas. Consideramos entonces que el análisis por QEMSCAN y la petrografía brindan información complementaria, y su aplicación combinada presenta gran potencial para estudiar proveniencia de materiales cerámicos y conocer las opciones tecnológicas implicadas en la manufactura de pastas.

En el futuro se espera realizar análisis de QEMSCAN a las muestras de potenciales materias primas del área de estudio, analizadas por petrografía y a una mayor cantidad de tiestos de procedencia trasandina, para testear las relaciones establecidas entre su composición y la de las pastas cerámicas.

\section{Agradecimientos}

Agradecemos a los organizadores del Simposio de avances en análisis de cerámica y pigmentos, Isabelle Druc y Jalh Dulanto, por su predisposición para facilitar nuestra participación en el simposio y por invitarnos a formar parte de este volumen. Extendemos nuestro agradecimiento a los expositores y asistentes al simposio; a la Pontificia Universidad Católica del Perú; a la Unidad de Equipamiento Científico MAINI, de la Universidad Católica del Norte, por el apoyo en la generación de datos mediante Microscopía Electrónica Automatizada QEMSCAN ${ }^{\circledR}$, a María Florencia Márquez-Zavalía, y Miguel Ángel Galliski por su apoyo y guía en los análisis petrográficos. Finalmente agradecemos a Andrew Menzies, y Monserrat Barraza, Ramiro Barberena, Víctor Durán y Valeria Cortegoso por su apoyo para la realización de los análisis. Este trabajo se llevó a cabo con el apoyo de CONICET, en el marco de proyectos (PICT 2014-0940, PICTO-20160056) subsidiados por ANPCyT y SECTyP UNCuyo.

\section{Notas}

${ }^{1}$ En este trabajo tomamos el concepto de inclusión adoptado por Druc y Chávez (2014) que refiere a cualquier material no arcilloso que se encuentra en la pasta. Utilizaremos los términos antiplástico, inclusiones, fracción no plástica de manera indistinta para referirnos al material no plástico presente en la pasta de un tamaño superior a $15 \mu$ (Curtois 1976) y que se diferencia de la matriz por su granulometría (Cremonte y Bugliani 2006-2009), independientemente de si este fue agregado o se encuentra naturalmente incluido en la pasta, cuestión que a priori cualquier análisis desconocemos.

2 Se utilizan los términos propuestos por Cremonte y Bugliani (2006-2009) para diferenciar las inclusiones minerales (cristaloclastos) de las inclusiones de fragmentos o clastos de rocas (litoclastos).

${ }^{3}$ Utilizamos la categoría cubierta dado que la discriminación entre engobe, falso engobe y pintura implica dificultades y puede resultar poco segura sin haber realizado un análisis de pigmentos, sobre todo a partir de la observación de conjuntos fragmentados. Incluimos en esta categoría cerámica con superficies a las que se les aplicó algún tipo de cobertura (ya sea engobe o pintura).

${ }^{4}$ Se trata de superficies que presentaron sectores erosionados y rastros de una cubierta de tono similar a las pastas, muy delgada, desleída, con microgrietas y fracturas, podría tratarse de un engobe de acuerdo a los criterios de López (2000-2002) y Rye (1981). 


\section{REFERENCIAS}

Arnold, D. (1985). Ceramics theory and cultural process, Cambridge University Press, Cambridge.

Arnold, D. (2006). The threshold model for ceramic resources: A refinement, en: D. Gheorgiu (ed.), Ceramic studies: Papers on the social and cultural significance of ceramics in Europe and Eurasia from prehistoric to historic times, BAR International Series 1553, 3-9, Archaeopress, Oxford.

Barraclough, A. (1992). Quaternary sediment analysis: A deductive approach at A-level, Teaching Geography 17, $15-18$.

Canals Frau, S. (1956). Algunos aspectos de la cultura de Agrelo, Anales de Arqueología y Etnología XIL,7-18.

Chiavazza, H. y V. Cortegoso (2004). De la cordillera a la llanura: disponibilidad regional de recursos líticos y organización de la tecnología en el norte de Mendoza, Argentina, Chungara, Revista de Antropología Chilena 36, 723-737.

Cornely, F. (1958). Cultura El Molle, Arqueología Chilena 4: 1-4.

Cortegoso, V. (2004). Organización tecnológica: explotación de recursos líticos y el cambio en la subsistencia de cazadores a agricultores en el N.O de Mendoza, tesis de doctorado, Facultad de Ciencias Naturales y Museo, Universidad Nacional de La Plata.

Cortegoso, V. (2006). Comunidades agrícolas en el valle de Potrerillos (NO de Mendoza) durante el Holoceno Tardío: organización de la tecnología y vivienda, Intersecciones en Antropología 7, 77-94.

Cremonte, M. B. y M. F. Bugliani (2006-2009). Pastas, formas e iconografía. Estrategias para el estudio de la cerámica arqueológica, Xama 19, 239-262.

Courtois, L. (1976). Examen au microscope pétrographique des céramiques archéologiques, Centre National de la Recherche Scientifique, Paris.

Druc, I. (2013). What is local? Looking at ceramic production in the Peruvian highlands and beyond, Journal of Anthropological Research 69, 485-513. https://doi.org/10.3998/jar.0521004.0069.404

Druc, I. y L. Chávez (2014). Pastas cerámicas en lupa digital: componentes, textura y tecnología, Deep University Press.

Durán, V. y C. García (1989). Ocupaciones Agro- Alfareras en el sitio Agua de la Cueva Sector Norte (NO de Mendoza), Revista de Estudios Regionales 3, 29-64.

Falabella, F., L. Sanhueza y E. Fonseca (2002). Una propuesta sobre la naturaleza de las materias primas de la cerámica Aconcagua Salmón, Chungara Revista de Antropología Chilena 34(2), 167-189.

Folguera, A., M. Etcheverría, P. J. Pazos, L. Giambiagi, L. Fauqué, J. M. Cortés, M. F. Rodríguez, M. V. Irigoyen y C. Fusari (2004). Hoja Geológica 3369-15, Potrerillos. Provincia de Mendoza. Instituto de Geología y Recursos Minerales, Servicio Geológico Minero Argentino, Buenos Aires.

Frigolé, C. (2017). Tecnología cerámica y movilidad en contextos de cambio. Alfarería del primer milenio A.D en la zona cordillerana de Mendoza, tesis de doctorado, Facultad de Filosofía y Humanidades, Universidad Nacional de Córdoba.

Frigolé, C. y A. Gasco (2016). Potters and herders at the southern edge of the Andean world: Risk management and mobility in Northwestern Mendoza, Argentina, Quaternary International 422, 152-162. https://doi. org/10.1016/j.quaint.2016.02.032

Frigolé, C., R. Moyano y D. Winocur (2014). Comparando la composición química y petrográfica de distintos estilos cerámicos en una casa del valle de Potrerillos (Mendoza, Argentina), en: V. Cortegoso, V. Durán y A. Gasco (eds.), Arqueología de ambientes de altura de Mendoza y San Juan (Argentina), 361-417, EDIUNC, Universidad Nacional de Cuyo.

Gambier, M. (2000). Prehistoria de San Juan, Ansilta editorial, San Juan.

García, A. (1994). Nuevas Perspectivas para el estudio de la cultura de Agrelo, Revista de Estudios Regionales 12, 19-27.

Hammer, K., D.A.T. Harper, P.D. Ryan. (2001). PAST: Paleontological statistics software package for education and data analysis. Palaeontologia Electronica 4(1), 9. http://palaeo-electronica.org/2001_1/past/issue1_01.htm

Knappett, C., D. Pirrie, M.R. Power, I. Nikolakopoulou, J. Hilditch y G.K. Rollinson (2011). Mineralogical analysis and provenancing of ancient ceramics using automated SEM-EDS analysis (QEMSCAN@): a pilot study on LB I pottery from Akrotiri, Thera. J. Archaeological Science 38 (2), 219-232. https://doi.org/10.1016/j. jas.2010.08.022

López, M. (2000/2002). Técnicas de acabado de superficie de la cerámica arqueológica: Indicadores macro y microscópicos. Una revisión sobre las técnicas de estudio más habituales. Cuadernos del Insitituto Nacional de Antropologia y Pensamiento Latinoamericano 19, 347-364.

Matthew A.J., A.J. Woods y C. Oliver (1991). Spots before the eyes: new comparison charts for visual percentage estimation in archaeological material, en: A. Middleton e I. Freestone (eds.), Recent developments in ceramic petrology, 211-254, British Museum Press, London. 
Menzies, A., M. Uribe, F. Erazo, C. Ossandon y P. Fonseca (2015). Automated mineralogical analysis of archaeological samples from northern Chile - Case Study II - Ceramics, XIV Congreso Geológico Chileno, La Serena.

Moyano, R. y C. Frigolé (2013). Replicando cocciones de la cerámica proveniente del sitio San Ignacio (NO de Mendoza). Cuadernos del Instituto Nacional de Antropología y Pensamiento Latinoamericano, Series Especiales 1 (2), 72-78.

Niemeyer, H., G. Castillo y M. Cervellino (1989). Los primeros ceramistas del Norte Chico: Complejo El Molle (0 a 800 d. C.), en: V. Schiappacasse, H. Niemeyer, C. Aldunate e I. Solimano (eds.), Culturas de Chile, Prehistoria, 227-263. Editorial Andrés Bello, Santiago.

Orton, C., P. Tyers y A. Vince (1993). La cerámica en arqueología, Crítica, Barcelona.

Pirrie, D., A.R. Butcher, M.R. Power, P. Gottlieb y G.L Miller (2004). Rapid quantitative mineral and phase analysis using automated scanning electron microscopy (QemSCAN); potential applications in forensic geoscience, en: K. Pye y D. Croft (eds.), Forensic geoscience: Principles, techniques and applications, Geological Society, Special Publication 232, 123-136, London. https://doi.org/10.1144/GSL.SP.2004.232.01.12

Riera-Soto, C. (2019). Circulación de cerámicas formativas en la cuenca del río Vilama: Nuevos aportes desde la tecnología., tesis de maestría, Programa de Postgrado en Antropología mención Arqueología, Universidad Católica del Norte, San Pedro de Atacama.

Rye, O. S. (1981). Pottery technology: Principles and reconstruction, Taraxacum, Washington D. C.

Sanhueza, L. (2004). Estilos tecnológicos e identidades sociales durante el período Alfarero Temprano en Chile central: una mirada desde la alfarería, tesis de maestría en Arqueología, Universidad de Chile, Santiago.

Schwartz, G. (1958). Alteration of biotite under mesothermal conditions, Economic Geology 53, 164-177. https:// doi.org/10.2113/gsecongeo.53.2.164

Winocur, D. A. (2014). Geología del valle del Cura, Cordillera Frontal, provincia de San Juan, en: V. Cortegoso, V. Durán y A. Gasco (eds.), Arqueología de ambientes de altura de Mendoza y San Juan, capítulo 10, 49, Ediunc, Mendoza.

Winocur, D.A., V.D. Litvak y V.A. Ramos (2015). Magmatic and tectonic evolution of the Oligocene Valle del Cura basin, main Andes of Argentina and Chile; Evidence for generalized extension, Geodynamic Processes in the Andes of Central Chile and Argentina, GSL Special Publications. doi:10.1144/SP399.2. https://doi. org/10.1144/SP399.2 